\title{
Notas para um estudo sobre a Unión de Cinematecas de América Latina
} Notes for a study on the Unión de Cinematecas de América Latina

\author{
Fabián Núñez
}

1 Professor adjunto do Departamento de Cinema e Vídeo da Universidade Federal Fluminense (UFF), desde 2009 e membro da Associação Brasileira de Preservação Audiovisual (ABPA), fazendo parte de sua direção durante a gestão 2012-2014. Atua na organização do Cineclube Sala Escura, projeto de extensão vinculado ao LIA (Laboratório de Investigação Audiovisual), desde 2010. É pesquisador da Plataforma de Reflexão sobre o Audiovisual Latino-Americano (PRALA) e do Laboratório Universitário de Preservação Audiovisual (LUPA). E-mail: fabian_nunez@id.uff.br. 
Resumo: $\mathrm{O}$ presente artigo visa lançar as bases para uma análise da formação da Unión de Cinematecas de América Latina (UCAL). Criada em 1965, a UCAL visa dar visibilidade e articulação às jovens cinematecas latinoamericanas. Por sua vez, a segunda metade dos anos 1960 pode ser interpretada como a consolidação ideológica do Nuevo Cine Latinoamericano (NCL), o que também põe em questão o papel de uma cinemateca em nosso subcontinente. A partir das reflexões de Borde e Correa Júnior sobre a história das cinematecas, visamos analisar o caso latino-americano ao entendermos a discussão sobre a instituição "cinemateca" como fundamental para os estudos sobre o cinema na América Latina, especialmente para contribuir em uma visão menos homogeneizante do Nuevo Cine Latinoamericano.

Palavras-chave: Unión de Cinematecas de América Latina; Nuevo Cine Latinoamericano; cinemateca; cinema na América Latina

Abstract: This article aims to lay the groundwork for an analysis of formation of Unión de Cinematecas de América Latina (UCAL). Created in 1965, the UCAL aims to give visibility and coordination to the young Latin American film archives. In turn, the second half of the 1960s can be interpreted as the ideological consolidation of the Nuevo Cine Latinoamericano (NCL), which also puts into question the role of an film archive in our subcontinent. Starting from the reflections of Borde and Correa Junior on the history of film archives, we aim to analyze the Latin American case because we understand the discussion of the institution "film archive" as fundamental for studies on cinema in Latin America, especially to help to a less homogenizing view of the Nuevo Cine Latinoamericano.

Key words: Unión de Cinematecas de América Latina; Nuevo Cine Latinoamericano; film archive; cinema in the latin américa. 


\section{Precisamos falar sobre cinemateca nos estudos de cinema latino-americano}

O presente artigo visa sistematizar algumas informações sobre a formação e a consolidação da Unión de Cinematecas de América Latina (UCAL). Logo, avisamos ao leitor que se trata de uma pesquisa em andamento, pois ainda faltam muitas lacunas a serem preenchidas, sobretudo em relação às dissidências ocorridas no seio da UCAL, a partir de meados dos anos 1970, o que culmina em seu desaparecimento na década seguinte. Por sua vez, a segunda metade dos anos 1960 pode ser interpretada como a consolidação ideológica do Nuevo Cine Latinoamericano (NCL), na medida em que já não se fala em nome de cinematografias nacionais, mas de uma cinematografia de caráter subcontinental, embora se reconheçam as singularidades de cada país. Portanto, não é mera coincidência o fato de os principais textos teóricos do NCL terem sido redigidos nesse contexto. Desse modo, da segunda metade dos anos 1960 e ao longo da década seguinte, o NCL se formaliza e busca postular os seus preceitos e pressupostos, formando um processo diversificado e múltiplo. E no interior deste processo se encontram os debates ocorridos na UCAL, sobretudo na discussão sobre a redefinição do conceito de cinemateca na América Latina. Portanto, o intuito de nossa pesquisa em andamento é compreender os discursos que atravessam a "instituição cinemateca" em nossos países no seio da UCAL, tomando o NCL como um vetor chave neste processo. Assim, o presente artigo visa acima de tudo levantar questões e publicizar preocupações de pesquisa com o intuito de postular uma reflexão sobre uma questão fundamental que é posta na virada dos anos 1960 para os 1970: qual é o papel de uma cinemateca na América Latina?

As primeiras cinematecas da América Latina começam a surgir após o término da Segunda Guerra Mundial, sobretudo, a partir da virada dos anos 1940 aos 1950. Um dos principais impulsionadores de suas criações é Henri Langlois, o mítico fundador da Cinemateca Francesa, que por intermédio de doação de cópias de filmes considerados esteticamente importantes na história do cinema (em sua maioria, obras francesas), ajuda a criar os fundos das recém-criadas cinematecas. Em alguns casos, tais lotes precedem as instituições de guarda, que surgem, então, estimuladas pelo empenho de importantes figuras locais do âmbito cinematográfico e cultural, por sua vez, apoiados, estratégica e externamente, por Langlois. Segundo Martínez Carril (2009), podemos, a grosso modo, resumir a história das cinematecas latinoamericanas em três momentos. Inicialmente, temos as primeiras cinematecas criadas por iniciativa de particulares, mais especificamente, por críticos e colecionadores - e, 
como frisa Correa Júnior (2012), esse impulso inicial se concentra em um núcleo duro, formado por Argentina (Buenos Aires), Brasil (São Paulo e, logo a seguir, Rio de Janeiro), Uruguai (Montevidéu) e Cuba (Havana). Um segundo momento, nos anos 1960, vemos a criação das cinematecas universitárias, por exemplo, a Cinemateca (atual Filmoteca) da UNAM (Universidad Nacional Autónoma de México) e as cinematecas universitárias do Chile, Peru e Guatemala. Por último e mais recente, as cinematecas públicas, quando os Estados latino-americanos tomam uma relativa consciência da importância cultural do cinema, incluindo também a de sua memória (ou seja, não somente a produção e difusão) ${ }^{2}$. Com certeza, a história de nossas cinematecas é bastante tumultuada - o que não poderia deixar de ser, seja por conta das reviravoltas políticas e dos constrangimentos econômicos de nossos países quanto pelas dificuldades inerentes às políticas culturais de nossos governos. Nesse sentido, basta vermos os vários casos de cinematecas latino-americanas que tiveram vida efêmera.

Já em 1955, surge a Seção Latino-Americana da Federação Internacional de Arquivos de Filmes (FIAF), congregando as novas cinematecas. No entanto, em 1960, estoura uma forte crise no seio da FIAF, culminando na saída da Cinemateca Francesa da organização. Em solidariedade à sua congênere gaulesa, em especial, a Langlois, a expressa maioria das cinematecas latino-americanas também se retiram da FIAF (com as notórias exceções do uruguaio SODRE e da Cinemateca de Cuba). Portanto, é por conta da retirada da Cinemateca Francesa da FIAF, que é criada a Unión de Cinematecas de América Latina (UCAL), pois as nossas cinematecas necessitavam de um novo espaço de aglutinação e visibilidade internacional, uma vez que a Seção Latino-Americana da FIAF, simples e obviamente deixara de existir.

Desse modo, a Unión de Cinematecas de América Latina (UCAL) é criada em 1965, em Mar del Plata, na Argentina, durante a realização do célebre festival local de cinema. Em setembro do mesmo ano (1965), por ocasião do I Festival Internacional do Filme (FIF), no Rio de Janeiro, é realizado outro encontro, com o propósito de ratificar a ata de fundação da recém-criada instituição. No entanto, é a

2 Frisamos que este panorama histórico feito por Martínez Carril necessita de alguns ajustes. Durante a nossa apresentação no III Congresso Internacional da AsAECA (Asociación Argentina de Estudios de Cine y Audiovisual), realizado em Córdoba, em maio de 2012, quando apresentamos um esboço da presente pesquisa, a pesquisadora uruguaia Mariana Amieva nos chamou a atenção para os comentários tendenciosos do conservador da Cinemateca Uruguaia. Por exemplo, na citada entrevista, Martínez Carril desconsidera a criação em 1943 do Departamento de Cinema do SODRE (Servicio Oficial de Difusión Radio Eléctrica; atual Servicio Oficial de Difusión, Radiotelevisión y Espectáculos) e sua filiação à FIAF desde 1945, ou seja, antes da fundação da Cinemateca Uruguaia, ocorrida em 1952. Portanto, podemos afirmar que o Departamento de Cinema do SODRE, o atual Arquivo Nacional da Imagem e da Palavra, é a primeira cinemateca latino-americana a ser membro da FIAF. Em suma, em relação à entrevista concedida por Martínez Carril, ressalta-se o quanto a rivalidade entre as cinematecas acaba sempre por se impor. 
partir do V Congresso da UCAL, realizado em Montevidéu em 1971, que podemos testemunhar no seio da instituição um discurso "terceiro-mundista", sobretudo no tema chamado "redefinição do conceito de cinemateca na América Latina". Esse processo culmina na Declaração Final e na reformulação dos Estatutos da UCAL aprovados pelo VI Congresso, realizado em 1972 na Cidade do México. Portanto, a UCAL surge, inicialmente, visando preencher um vazio institucional, mas, devido à "radicalização política", cria-se uma cisão em seu seio, que ocorre de vez no VIII Congresso da entidade, realizado em concomitância com o XXXII Congresso da FIAF. Martínez Carril rememora:

Em um momento se deu uma tentativa de hegemonia política de concepção foquista no político e no cultural por parte dos cubanos (não de Héctor García Mesa, o esclareço) e as cinematecas que estavam na mesma tendência, mais um grupo animado pelo princípio teórico de "todo poder aos cineastas". Isso é o que surge das reuniões da UCAL em Viña del Mar [em 1967] e logo na Venezuela [em 1974], quando se produz o ponto de quebra. A partir daí, há duas linhas de pensamento: a que está em torno de Cuba e outra, que é um pouco a nossa também [se refere à Cinemateca Uruguaia], e que se desenvolve ao redor do projeto de Nelson Pereira dos Santos, no Rio, segundo a qual é o público e as pessoas, e não nós quem temos a verdade. (...). A discussão sobre isso foi interminável. A UCAL desaparece simplesmente porque se desvanece. Enquanto isso, os arquivos que formamos a Coordenadora de Cinematecas do Cone Sul mais Peru, continuamos fora da UCAL. A discussão continuou durante um Congresso da FIAF no México em 1976. Está Pastor Vega pela Cinemateca de Cuba, há um africano, Mboula, etc. Nesse Congresso, estávamos [Walther] Dassori e eu [como representantes da Cinemateca Uruguaia]. Héctor García Mesa estava presente, mas não podia falar. É aí que se rompe a unidade latinoamericana (CARRIL, 2009, p. 51).

Domínguez (2013) relata os pormenores da cisão: os representantes das Cinematecas Uruguaia (Martínez Carril) e Argentina (Guillermo Fernández Jurado) desautorizam a UCAL frente à FIAF, ao afirmar durante o XXXII Congresso que a entidade não representava mais a totalidade das cinematecas da região. Relatam aos delegados da FIAF que, no início de 1975, havia sido criada a Regional de Cinematecas do Cone Sul, fundada por Cinemateca Argentina, Cinemateca Uruguaia, o SODRE e a Cinemateca Paraguaia, ao considerar que a UCAL "não representava nem podia representar a América Latina”.

A partir do começo dos anos 1980, começa um movimento de reaproximação das duas vertentes. Trata-se de uma iniciativa de ambos os lados, em busca de uma solução para a reintegração de todas as cinematecas do subcontinente latinoamericano em uma mesma instituição. Desse modo, em abril de 1985, no México, 
é formalmente criada a CLAIM (Coordinadora Latinoamericana de Archivos de Imágenes en Movimiento), graças sobretudo aos esforços do brasileiro Cosme Alves Netto (Cinemateca do MAM) e do mexicano Manuel González Casanova (Filmoteca da UNAM), ao ter como instituições fundadoras, além das duas citadas acima, as Cinematecas Argentina, Boliviana, Brasileira, de Cuba, Uruguaia e a Cineteca Nacional do México.

Em seu já clássico livro, Borde (1983) traça a história das cinematecas num relato da passagem de uma época inicial marcada pela subjetividade em direção à consolidação da atual objetividade técnica. A origem das cinematecas, em sua expressa maioria, se deve a particulares, como críticos, cineclubistas e colecionadores, criando um forte vínculo entre esses intelectuais e tais instituições. Assim, o personalismo é a principal marca dos anos iniciais das cinematecas. No entanto, com uma progressiva conscientização da conservação das obras audiovisuais, foi sendo criada uma nova percepção no seio dessas instituições de guarda, deslocando a ênfase nos aspectos estéticos - e, por conseguinte, do fundamental arbítrio por parte de uma história estética da arte cinematográfica - para aspectos puramente técnicos. Assim, se dirige a uma necessária interatuação entre a ciência da informação, de princípios básicos de física e química dos suportes audiovisuais, conhecimentos de gestão e de uma história não apenas estética, mas também tecnológica dos meios e processos audiovisuais, entre outras áreas de caráter técnico-científico. Então, aos poucos, um determinado perfil de profissional exigido para atuar em uma cinemateca foi sendo consolidado, a par da atual noção de conservação que rege essas instituições de guarda.

Correa Júnior sublinha o tom teleológico na obra de Borde, como se a instauração da atual objetividade técnica tenha ocorrido de modo quase que natural e inexorável. E nesse sentido, a "Crise de 1959/60" ocorrida no seio da FIAF, com todo o trauma ocasionado, foi central para esta virada. Porém, segundo Correa Júnior, para compreender esta "passagem da subjetividade à objetividade técnica", há um fenômeno mais profundo, que parece escapar à leitura de Borde: o surgimento de um mercado do patrimônio cinematográfico, que as cinematecas paradoxalmente ajudaram a criar. Recorremos às palavras de Correa Júnior que sintetizam muito bem a sua ideia:

Para Borde, a crise das cinematecas [que estoura em 1959/60] (...) se originou na falta de percepção de que, na ausência de recursos materiais para preservar $e$ difundir os filmes, as cinematecas não deveriam ter dúvidas quanto à escolha (...): a conservação dos filmes. (...)

Sem desprezar os problemas e a necessidade de investimento na preservação dos filmes queremos ampliar o foco para 
compreendermos melhor o que de fato parece estar na base da crise: a formação (e ampliação) de um novo mercado do direito autoral para os velhos filmes, e por consequência de um mercado do patrimônio cinematográfico. De algum modo o problema está na origem do conceito de cinemateca, e diz respeito à natureza mesma de seu objeto privilegiado: o cinema; arte e indústria a um só tempo. (CORREA JUNIOR, 2012, pp. 14-5)

Apoiamos a crítica de Correa Júnior a Borde em relação ao tom teleológico que, por vezes, soa na visão do autor francês. No entanto, concordamos com Borde e Buache (1997), pois houve, de fato, uma transformação radical no universo das cinematecas, sobretudo a partir dos anos 1950, com o advento da televisão comercial, quando a própria indústria cinematográfica se vê diante do prolongamento da vida comercial dos filmes "antigos". Assim, "juntar filme velho" deixa de ser uma excêntrica ação de um estreito grupo de fanáticos para se tornar uma prática corrente da própria indústria. Soma-se a esse fator, a consolidação do conceito de patrimônio na área audiovisual, o que transforma o sentido dos arquivos fílmicos, que passam a ser encarados como algo digno da alçada do Estado e de instituições multilaterais, como a UNESCO. Desse modo, Borde e Buache afirmam que "os anos heroicos" da formação das cinematecas foram revolvidos, dando lugar a uma nova era, a partir da segunda metade do século passado. Portanto, para nós, atualmente, há um tom romântico que circunda os primeiros anos das cinematecas, quando figuras à sua frente eram homens obstinados em aumentar os seus acervos, à revelia de produtores e distribuidores, movidos acima de tudo pela paixão ao cinema. Hoje em dia, os profissionais que dirigem os arquivos audiovisuais são meros administradores de patrimônio sem o mesmo carisma e a "aura" de intelectuais cinéfilos de seus predecessores, de quem nós saboreamos as suas histórias dos "tempos heroicos".

No entanto, se as cinematecas, em sua missão institucional de preservar e difundir filmes, ajudaram - inconscientemente - a criar um mercado do patrimônio cinematográfico, isso se deve, inicial e principalmente, a uma política por elas adotadas, a saber, a de consagrar o cinema como manifestação artística. Portanto, a ação da cinefilia, que é inconcebível sem os cineclubes e as cinematecas, foi um fatorchave no advento do chamado Cinema Moderno. É esse o paradoxo que norteia as reflexões de Correa Júnior. Cremos que tais questionamentos são bastante instigantes e, por conseguinte, fundamentais para pensarmos o fenômeno das cinematecas em nosso contexto subcontinental. Na América Latina e, em especial, em relação ao NCL, testemunhamos o mesmo processo. A expressa maioria dos cineastas modernos latino-americanos iniciam as suas vidas como cineclubistas, críticos e, sobretudo, 
assíduos frequentadores de cinematecas (às vezes, chegaram até a trabalhar em uma delas). Aliás, recordamos que as nossas primeiras cinematecas surgem como iniciativa de críticos e colecionadores de filmes (não podemos nos esquecer da exceção do pioneiro SODRE, já que é um órgão público).

Ao analisarmos a abordagem da preservação audiovisual pelas principais revistas especializadas cinematográficas latino-americanas, vinculadas ao ideário do NCL, podemos notar aparentemente um primado da difusão e da realização sobre os aspectos inerentes à preservação. A noção combatida de que a cinemateca seria um mero arquivo cinematográfico para uma pequena elite evidencia as fortes ressalvas a uma acepção "cinefílica" da cinemateca, ou seja, em seu sentido "tradicional francês" conforme estudado por Baecque (2011), que, paradoxalmente ou não, desempenhou um importantíssimo papel no boom dos "cinemas novos" ao redor do mundo. A assimilação desse discurso "esquerdista" pelas revistas especializadas analisadas, quando não o mais profundo silêncio sobre o tema, demonstra que os próprios redatores, mesmo os mais próximos à "cinefilia", no sentido francês, se vinculam antes aos postulados político-ideológicos do NCL do que às suas íntimas paixões estéticas. Em suma, no elenco dos temas abordados, a preservação se vê subordinada à ânsia de produção e difusão do NCL. O NCL sofreria do pressuposto (preconceito?) de que é necessário primeiro fazer e divulgar os filmes, para depois, se preocupar em conservá-los (legar para as próximas gerações)? Ironicamente, o NCL não estaria reproduzindo uma mentalidade entranhada na classe cinematográfica latino-americana de, antes de mais nada, filmar, postergando para depois o que tradicionalmente é considerado o que vem depois (a difusão e, por última etapa, a conservação e, caso derradeiro, a restauração)? Afinal, essa subestimação da preservação não é coerente com a postura generalizada do NCL de recusa de boa parte da memória cinematográfica nacional, considerada deletéria e alienada? No entanto, voltemos ao objeto de nossa pesquisa atualmente em andamento: a presença da UCAL no discurso do NCL (que frisamos, não se trata de um discurso unívoco e consensual). Portanto, as nossas questões-chave são: que papel a UCAL desempenha (ou deveria desempenhar, dependendo das vertentes no seio do NCL) em relação ao NCL? Seria a crise que se instaura no seio da UCAL, a partir da primeira metade dos anos 1970, uma versão local da "Crise de 1959/60", ocorrida na FIAF? Caso seja, que linhas podemos traçar entre as divergências no seio da UCAL com a então incipiente consolidação do mercado de patrimônio cinematográfico em nossos países? Qual deveria ser a função de uma cinemateca em países sem indústria cinematográfica, como é o caso latino-americano? 


\section{UCAL: origem e formação}

A UCAL é formalmente fundada em Mar del Plata, em março de 1965, com a presença de Rolando Fustiñana (Cinemateca Argentina), Oscar Hansen (Instituto Nacional de Cinematografía - Argentina), Rudá de Andrade (Cinemateca Brasileira), Pedro Chaskel (Cineteca da Universidade do Chile), Manuel González Casanova (Departamento de Cinematografia da UNAM), Miguel Reynel (Cinemateca Universitária do Peru) e Walther Dassori (Cinemateca Uruguaia). Segundo o texto de fundação, por razões geográficas e dificuldades de intercâmbio, a instituição é pensada em três zonas: 1) Argentina, Brasil, Chile, Paraguai e Uruguai; 2) Bolívia, Colômbia, Equador, Peru e Venezuela e 3) México e América Central. É nomeada uma comissão provisória integrada por três secretarias delegadas de Argentina, México e Peru, com os seguintes objetivos: organizar o primeiro Congresso, a ser realizado no prazo de um ano, formular um projeto de estatutos e estimular o intercâmbio de material fílmico. Em setembro desse mesmo ano (1965), ocorre uma reunião no Rio de Janeiro durante o I FIF, que culmina na Ata de Ratificação da UCAL. Estão presentes Carmen Toscano (Cinemateca do México) ${ }^{3}$, Margot Benacerraf (Cinemateca do Instituto Nacional de Cultura e Belas Artes - Venezuela), José Sanz (Cinemateca Nacional - Brasil) ${ }^{4}$, Francisco Luiz de Almeida Salles (Cinemateca Brasileira), Juan Carlos Fissner (Cinemateca Argentina), Hernando Salcedo Silva (Cinemateca Colombiana), Manuel González Casanova (Cinemateca da UNAM), Kerry Oñate (Cineteca da Universidade do Chile), Miguel Reynel (Cinemateca Universitária do Peru) e Walther Dassori (Cinemateca Uruguaia). São declaradas três categorias de membros na UCAL: os efetivos, os provisórios e os postulantes, incluindo-se, no primeiro caso, as cinematecas da Argentina (Cinemateca Argentina e o Instituto Nacional de Cinematografía), a Cinemateca Brasileira, a Cineteca da Universidade do Chile, a Cinemateca Universitária do Peru, a Cinemateca

\footnotetext{
3 Desconhecemos o que seja essa denominação. Talvez seja a atual Cineteca Nacional. Ressaltamos que a Cineteca Nacional do México é formalmente criada por lei em 1949, sendo que já existia uma autodenominada Filmoteca Nacional, criada em 1936, a partir de colecionadores de filmes. Somente em 1971, o governo mexicano cria uma sede para a atual Cineteca, passando a existir fisicamente e não mais no papel. É graças à formalização da Cineteca Nacional que o arquivo fílmico da UNAM, criado em 1960, passa a se chamar Filmoteca da UNAM em 1974. Frisamos que Carmen Toscano é filha do pioneiro do cinema mexicano, Salvador Toscano, cujo arquivo fílmico particular constitui atualmente a Fundação Carmen Toscano, criada em 1992, sendo membro da FIAF.

4 Apesar da existência da Cinemateca Brasileira, em São Paulo, e da Cinemateca do MAM, no Rio de Janeiro, ambas então instituições particulares, o Instituto Nacional de Cinema (INC) cria formalmente uma Cinemateca Nacional. Souza (2009) afirma que a criação dessa Cinemateca se deu por intermédio da Resolução INC 34/70, sendo revogada pela Resolução 185/89, pelo Conselho Nacional de Cinema (CONCINE), uma vez que a Cinemateca Brasileira passou a ser um órgão federal, a partir de 1984. Em nossas pesquisas, encontramos uma carta de Miguel Reynel, datada de 13 de maio de 1968, dirigida a José Sanz, tratando-o como diretor da Cinemateca Nacional, cujo endereço é Praça da República n ${ }^{\circ} 141$ - A, Rio de Janeiro, ou seja, o endereço do INC (Acervo da Cinemateca do MAM).
} 
Colombiana e a Cinemateca Uruguaia. Na segunda categoria, a de membros provisórios, a Cinemateca Nacional do Brasil e a Cinemateca do Instituto Nacional de Cultura e Belas Artes da Venezuela. Por fim, no último caso se encontrava a Cinemateca do México. Conforme podemos notar, há a presença na formação da UCAL de arquivos fílmicos particulares, universitários e públicos, incluindo estranhamente um órgão ligado mais à regulação do mercado cinematográfico do que à preservação de patrimônio (o caso do INC argentino), além de instituições existentes mais no papel do que fisicamente (o caso da Cinemateca Nacional do Brasil, vinculado ao nosso INC, e, provavelmente, também seja o caso da enigmática Cinemateca do México). É constituída a Comissão Provisória das Secretarias Delegadas da Argentina, México e Peru, com o objetivo de fomentar as relações entre as cinematecas da América Latina e organizar o Primeiro Congresso Internacional da UCAL, que muito provavelmente seria realizado no México (e efetivamente não ocorreu). Fica delegada à Cinemateca Universitária do Peru a formulação do projeto dos Estatutos da UCAL e, por último, incumbe-se à Cinemateca Argentina o assessoramento e a coordenação do intercâmbio de material fílmico. Fica acordado que todos os membros devem enviar mensalmente um informe sobre suas atividades para a Cinemateca da UNAM, que, por sua vez, se responsabiliza em publicá-los e reparti-los entre as instituições da entidade. Há, também, a assinalação de se estudar o ingresso da UCAL no Comitê dos Museus de Cinema do ICOM (International Council of Museums), além da intenção de convidar um observador da citada instituição para o congresso da UCAL. Também é citada a mesma ideia em relação a um representante da FIAF.

Chamamos a atenção de que o próprio Langlois esteve presente na criação da UCAL, uma vez que participou dos dois festivais em questão. ${ }^{5}$ Durante o I FIF, houve dois encontros financiados pela União Mundial de Museus de Cinema, organização criada por Langlois em contraposição à FIAF. Domínguez afirma, sem maiores pormenores, que o INC argentino buscou inicialmente ser o sistematizador da UCAL por ser um dos pioneiros e, talvez, o principal mentor de sua criação. Cremos que o INC brasileiro fazia parte desse processo, já que Antônio Moniz Vianna, então secretário-executivo do INC, também era o primeiro vice-presidente da União Mundial de Museus de Cinema. ${ }^{6}$ Logo, não podemos deixar de sublinhar a ironia do nascimento da UCAL estar vinculado a dois órgãos oficiais bastante criticados pelo NCL. Após o Golpe na Argentina em 1966, a associação de tais entidades com

5 Domínguez relata a tensão ocorrida durante o certame marplatense pelo francês, uma vez que também estava presente Jerzy Toeplitz, presidente da FIAF.

6 Chamamos a atenção para o uso da mesma terminologia utilizada tanto pela UCAL quanto pela instituição formada por Langlois: "união" e, não, "federação". 
os regimes militares vigentes em seus respectivos países torna-se direta aos olhos dos integrantes do NCL.

Em Viña del Mar, no começo de março de 1967, é realizado, paralelo ao I Encontro de Cineastas Latino-Americanos e ao V Festival de Cinema, o denominado III Congresso da UCAL, no qual são aprovados os Estatutos, a partir da proposta apresentada por Miguel Reynel. Encontram-se presentes nesse congresso, além de Reynel, Rudá de Andrade (Cinemateca Brasileira), Paulo César Saraceni (Cinemateca do MAM), Saúl Yelín (Cinemateca de Cuba), Kerry Oñate (Cineteca da Universidade do Chile), Walther Dassori (Cinemateca Uruguaia) e Margot Benacerraf (Cinemateca do Instituto Nacional de Cultura e Belas Artes - Venezuela). Pelos termos do Estatuto, são oficializadas as três já citadas secretarias, dispostas por área geográfica. Constitui-se, então, um fundo de filmes, formado por todos os membros da UCAL. Coube à secretaria das cinematecas da Argentina, Brasil, Chile e Uruguai realizar uma relação completa dos filmes que tais cinematecas possuem. Conforme os parágrafos 6 e 7 do item II do recém-aprovado Estatuto da entidade, o fundo de filmes da UCAL se encontra à disposição de cada membro para intercâmbios, empréstimos e programas especiais, sendo o gasto de transporte por parte da cinemateca solicitante (salvo exceções). Além disso, os negativos depositados no acervo dos membros se encontram disponíveis a todos para a feitura de contratipos e cópias, com o consentimento da cinemateca proprietária. Segundo os Estatutos aprovados, passam a existir dois tipos de membros, os efetivos e os provisórios, sendo necessários dois pré-requisitos básicos para solicitar o ingresso à entidade: “a) ter desenvolvido um trabalho devidamente comprovado no campo da cultura cinematográfica, sem fins comerciais; b) contar com um fundo de filmes". Como podemos ver, trata-se de algo bastante genérico, uma vez que sua atenção é mais focada na difusão do que nos compromissos de conservação e restauração. Também sublinhamos que um membro provisório adquire o status de efetivo por intermédio de uma votação, por escrito, entre os membros efetivos, ao alcançar a metade mais um dos votos.

Das decisões tomadas no III Congresso, destacamos a admissão oficial na UCAL da Cinemateca do MAM e da Cinemateca de Cuba na qualidade de membros provisórios. Além disso, é aprovada uma disposição transitória que cria um pool de filmes latino-americanos, a partir dos acervos dos membros da UCAL. Caberia a todas as cinematecas membros selecionar um lote de filmes em $16 \mathrm{~mm}$ de obras consideradas importantes de sua respectiva cinematografia e enviá-lo à Cinemateca da UNAM, que se responsabilizaria por realizar um ciclo de exibições, com a 
máxima publicidade. Posteriormente, esse lote de filmes seguiria um itinerário por vários membros da UCAL, onde também seriam exibidos, a partir da seguinte ordem: Cinemateca de Cuba, Cinemateca Colombiana, Cinemateca Universitária do Peru, Cineteca da Universidade do Chile, Cinemateca Argentina, Instituto Nacional de Cinematografia (INC) da Argentina, Cinemateca Uruguaia, Cinemateca Brasileira e, por último, a Cinemateca do MAM, que se responsabilizaria por devolver os filmes aos seus arquivos de origem. Desconhecemos se foi realizada essa mostra, de acordo com o itinerário proposto. Não podemos deixar de assinalar a precariedade nesses anos iniciais da UCAL relatada por Domínguez. A tão apregoada integração regional é marcada por demoradas e não respondidas correspondências entre seus integrantes, inclusive bastante próximos geograficamente, como entre Montevidéu e Buenos Aires, e pela forte dependência de favores pessoais e diplomáticos e da boa vontade de muitas pessoas.

Em relação ao IV Congresso da UCAL, realizado em Mar del Plata em 1968, não conseguimos até o atual estágio de nossas pesquisas coletar muitas informações. ${ }^{7}$

É a partir do V Congresso, realizado em Montevidéu, no mês de julho de 1971, que ocorre a "virada terceiro-mundista" da UCAL. Estiveram presentes os seguintes delegados: Guillermo e Paulina Fernández Jurado (Cinemateca Argentina, que também representou os interesses da Cinemateca Universitária do Peru e da Cinemateca Universitária Enrique Torres da Universidade de San Carlos de Guatemala), Cosme Alves Netto (Cinemateca do MAM), Rudá de Andrade (Cinemateca Brasileira e observador do MIS-SP), Pedro Chaskel (Cineteca da Universidade do Chile), Manuel González Casanova (Cinemateca da UNAM), Oscar Trinidad (Cinemateca Paraguaia), Walther Dassori, Luis Elbert, Manuel Martínez Carril (Cinemateca Uruguaia), Eugenio Hintz, Jorge Alvite (SODRE) e Perán Erminy (Cinemateca Nacional da Venezuela). O principal tema que rondou esse congresso foi a redefinição do conceito de cinemateca na América Latina. Assim, no início do evento, foi constituída uma comissão para redigir o texto, formada por delegados da Cinemateca do MAM, Cineteca da Universidade do Chile e da Cinemateca Uruguaia. Torna-se claro que o documento não necessariamente precisa ser uma declaração oficial da UCAL, mas apenas uma manifestação das cinematecas signatárias. No entanto, opta-se por ser uma expressão oficial, que ficou conhecida como a Declaração de Montevidéu, datada do último dia do Congresso (30 de julho de 1971). O parágrafo final da Declaração é conciso ao proclamar que "o ato cultural

7 A carta de Reynel a Sanz se refere a uma das resoluções tomadas no IV Congresso: o envio de uma declaração de apoio a Henri Langlois ao ministro da cultura francês André Malraux. Trata-se, como era de se esperar, de uma manifestação formal da UCAL contra a demissão de Langlois da direção da Cinemateca Francesa (Acervo da Cinemateca do MAM). 
por excelência na América Latina é a libertação de nossos povos e é a seu serviço que devem ser colocadas as atividades cinematográficas do continente". Ou seja, inclusive as ações de uma cinemateca, que deve, portanto, atender à missão de despertar a consciência crítica das massas trabalhadoras. Também podemos testemunhar o esforço oficialmente declarado de estreitar relações com a Cinemateca de Cuba pelos demais membros da UCAL, em sua maioria, prejudicados pelo rompimento das relações diplomáticas com a Ilha por parte de seus respectivos países. Por isso, coube aos delegados mexicano e chileno fazer a intermediação entre o arquivo fílmico de Havana e o restante do subcontinente. No ensejo do reinante espírito "terceiromundista”, deseja-se reformular os Estatutos. Coube à Cinemateca Paraguaia levar uma proposta de novos regulamentos para o congresso seguinte.

O VI Congresso, realizado em 1972 na Cidade do México, aprofunda o viés revolucionário, inclusive com a escrita de uma nova declaração, intitulada "Cultura nacional e descolonização cultural”, a cargo de uma comissão composta por Manuel González Casanova, Cosme Alves Netto e Pastor Vega. É registrada em ata a recusa do SODRE de subscrever a Declaração (acreditamos que tal recusa se deve por ser um órgão público e, por conseguinte, evitar problemas ao seu delegado, Eugenio Hintz, com as autoridades uruguaias). Ocorrem várias deliberações, como os novos Estatutos, mais detalhados; a criação do Centro de Informação e Documentação da UCAL (CIDUCAL), a cargo da Cinemateca da UNAM com um escritório regional na Cineteca da Universidade do Chile; a escrita coletiva de um Dicionário de Documentário Latino-Americano, a ser organizado pela Cinemateca do MAM que, por sua vez, também se responsabiliza por uma enquete sobre Eisenstein. Um dos tópicos importantes é o envio pelos membros ao Centro de Documentação da UCAL de relatos de casos de censura sofridos nos países das cinematecas da entidade. A sede da Secretaria Geral da UCAL é designada, por unanimidade, a Cineteca da Universidade do Chile, fixando o próximo Congresso a ser realizado no país andino.

No entanto, o Golpe de 1973 frustra tais planos, o que significa a reestruturação do secretariado. Portanto, parte da documentação da Secretaria é destruída, em especial no que se refere às Declarações de Montevidéu e México, além de toda a correspondência com a Cinemateca de Cuba, documentação sobre perseguição de cineastas e protestos. Pedro Chaskel, secretário-geral, viaja para a Argentina, onde se pretende organizar o próximo congresso da UCAL (o que não ocorre). Posteriormente, migra para Lima e, por fim, fixa seu exílio em Havana, onde cria e dirige a Cinemateca Chilena da Resistência, posteriormente, denominada Cinemateca Chilena do Exílio. Frente ao agravamento da situação política em nossa região, dois Congressos da UCAL são realizados na Venezuela, em 1974 e 
1977, concomitantemente aos IV e V Encontro de Cineastas Latino-Americanos. ${ }^{8}$ A Venezuela é escolhida como sede por ser considerada "território neutro", uma vez que devido ao caráter público do evento, caso ocorresse em Cuba, a presença oficial das delegações do subcontinente na Ilha poderia suscitar futuras repreensões aos seus integrantes. Por outro lado, a favorável conjuntura nas relações entre Venezuela e Cuba, em um período em que a maioria dos países do continente americano não mantinha relações com a Ilha, permitiria o ingresso da delegação cubana no país sede sem maiores transtornos. Frisamos que a aproximação do governo venezuelano com Cuba culmina no restabelecimento das relações diplomáticas entre os dois países, em dezembro de 1974. ${ }^{9}$ Pedro Chaskel é reeleito mais de uma vez no cargo de secretário-geral. Os dois congressos venezuelanos (1974 e 1977) são marcados pela denúncia da onda de repressões às cinematecas membros da UCAL e a vários cineastas latino-americanos durante a primeira metade da década, além de uma busca de aproximação com a UNESCO e com a FIAF, sobretudo por intermédio do cubano Saúl Yelín, eleito membro do Comitê Executivo da FIAF no XXIX Congresso da federação em Moscou, em 1973. Conforme os relatórios da UCAL, Yelín se transforma em uma figura chave na mediação entre as duas instituições (UCAL e FIAF), o que é bruscamente interrompido em 1977 devido à sua morte prematura. ${ }^{10}$ No entanto, Domínguez afirma que Yelín não é reeleito em 1976, quando ocorre a cisão no congresso mexicano, apesar de contar com os votos dos países socialistas. Aparentemente, a desautorização da UCAL frente à FIAF custou o posto do dirigente cubano. ${ }^{11}$ Portanto, ironicamente, é em território latino-americano que as divergências estouram publicamente no seio da UCAL, culminando no processo irreversível de ruptura e em sua futura dissolução. Nas palavras de Galvão (1991), a UCAL teve uma atuação mais política do que técnica ou cultural e cuja vida longa e conturbada foi marcada por dissidências internas que refletem "antes o conflito mais geral das diferentes facções da esquerda latino-americana da época”.

\footnotetext{
8 O VII Congresso seguiu o tom do IV Encontro: solidariedade ao povo chileno frente à ditadura implantada no país. Domínguez cita a recusa por parte das Cinematecas Argentina, Uruguaia e o SODRE de assinar a Declaração Final do congresso, que critica duramente o regime militar chileno.

9 Lembramos que o México foi um dos poucos países ocidentais a não romper relações diplomáticas com Cuba.

10 Segundo Chaskel, em entrevista concedida ao autor por correspondência eletrônica, nunca houve maiores relações entre a UCAL e a FIAF. Cita, no entanto, que ele acompanhou Yelín no XXXI Congresso da FIAF, em Turim, em 1975, para informar e denunciar a situação do cinema chileno sob a ditadura, em nome da Cinemateca Chilena do Exílio, que nunca foi ou postulou a ser membro da FIAF.
}

11 No site da FIAF, encontramos outra informação: Yelín é reeleito para o Comitê Executivo em 1976. 


\section{Rastros entre os cristais do passado e o vinagre da memória: reflexões finais}

Já afirmamos em outro texto (Núñez, 2012) sobre a necessidade de mais estudos para se compreender a trajetória de nossas cinematecas e a inter-relação entre elas, da Seção Latino-Americana da FIAF à CLAIM, passando pela experiência da UCAL. Não se trata de rastrear brigas pessoais, desavenças ou desafetos, embora as relações humanas, demasiadamente humanas, sejam inerentes aos processos históricos. Mas, sim, para melhor compreender as relações entre cineastas, produtores, cineclubes, arquivos e entidades estatais do âmbito cinematográfico e audiovisual na América Latina, sobretudo para entender melhor, em nosso caso, o fenômeno do NCL. Assim, o debate sobre a redefinição do conceito de cinemateca que, freme a virada dos anos 1960/70 na UCAL, pode ser lido como mais um capítulo do processo de consolidação simbólica do NCL. Talvez mais do que isso, estejam por trás desse debate as divergências internas do NCL, i.e, as divergências entre as vertentes "clandestina" e "industrial". Por outro lado, pelo que podemos constatar até agora, o diálogo entre os dirigentes das cinematecas latino-americanas parece bastante cordial nos anos 1980, todos coadunados com questões em comum, como condições financeiras e técnicas para se manter um arquivo filmográfico. A Filmoteca da UNAM torna-se o orquestrador desse convívio, ao organizar sob os auspícios da UNESCO os dois Seminários Latino-Americanos de Arquivos de Imagens em Movimento ${ }^{12}$, ambos realizados em Oaxtepec, o primeiro em 1980 e o segundo em 1982. ${ }^{13}$ Pelos informes que encontramos, podemos nos defrontar com textos bastante técnicos, inclusive traduções de artigos sobre conservação e catalogação de profissionais de arquivos filiados à FIAF. A presença de uma discussão mais técnica pode ser atribuída às novas preocupações que giram em torno dos profissionais latino-americanos que buscavam formação na Europa e/ou nos Estados Unidos. É o caso, por exemplo, de Francisco Gaytán, da Filmoteca da UNAM, o principal organizador dos dois Seminários citados acima, realizados após o seu estágio no Staatliches Filmarchiv da antiga Alemanha Oriental, onde também estudaram outros preservadores audiovisuais latino-americanos. O III Seminário (ou Encontro) ocorre no Brasil, em 1984, iniciado em São Paulo e finalizado no Rio de Janeiro, respectivamente nas Cinematecas Brasileira e do MAM. Sintomaticamente, os estertores da UCAL ocorrem sob os auspícios de México e Brasil, o que nos remete às ações conjuntas

12 Outro título que encontramos é Encontro de Arquivos de Imagens em Movimento da América Latina e do Caribe.

13 O II Encontro foi realizado logo em seguida ao XXXVIII Congresso da FIAF, também sediado em Oaxtepec. 
de Manuel González Casanova e Cosme Alves Netto em prol da concórdia entre as cinematecas latino-americanas. Segundo Galvão (1991), o Encontro brasileiro é a última reunião geral da UCAL, quando se chega a um impasse, pois a UCAL não é reativada nem tampouco oficialmente extinta. Em seus termos, "simplesmente deixou de existir".

Para uma interpretação desse processo é possível postular a hipótese de Borde da "passagem da subjetividade à objetividade técnica". Assim, tal processo acarretou na própria dissolução da UCAL e de sua estrutura, considerada demasiada e perigosamente burocratizante e centralizadora (o que justificaria o caráter tão "informal” da atual CLAIM). Galvão chama a atenção para os vários sentidos que os termos "cinemateca", "cineteca" ou "filmoteca" têm historicamente na América Latina. Mais do que nuances entre as línguas portuguesa e castelhana, trata-se de um entendimento, em boa parte dos casos, de que se trata de instituições culturais voltadas para a formação de um campo cinematográfico em países, em geral, sem nenhuma ou pouca tradição de produção fílmica local. Assim, as cinematecas adquirem uma missão focada primordialmente na difusão e na realização, o que pode ser confirmado em acervos formados apenas por cópias e não também por matrizes. ${ }^{14}$ Como pudemos perceber em seus Estatutos, os critérios bastante amplos de ingresso na UCAL denotam esse entendimento e, talvez, movido pelo objetivo de congregar a maior quantidade possível de instituições na federação. Caso tais critérios fossem bastante estritos, boa parte de nossas instituições, naquela época, não formariam parte de uma entidade de cinematecas, como as entendemos nos dias de hoje. No entanto, somos atentos às críticas de Correa Júnior ao viés teleológico de Borde, o que nos tornam vigilantes para a interpretação do processo de autodissolvência da UCAL. Assim, precisamos evitar um entendimento de que a transição para a "objetividade técnica", coroada com a dissolução da "centralizadora e política" UCAL e a criação da "informal e tecnicista" CLAIM, se deve a um suposto e inexorável processo histórico. Mais do que uma hipotética lei universal da História, trata-se de um fenômeno social que adquire conotações próprias, inerente ao conturbado período político de nosso subcontinente nos anos 1960 e 70 e, por conseguinte, às reviravoltas da esquerda local, especificamente em suas manifestações no seio da classe cinematográfica da América Latina, em especial, nos integrantes do NCL. Portanto, a entrada em cena de debates mais técnicos entre as cinematecas latino-americanas não somente pode ser lido como uma mudança geracional no

14 Por exemplo, Salinas Muñoz e Stange Marcus (2008) afirmam categoricamente que a Cineteca Universitária da Universidade do Chile, formada em 1960, voltava as suas ações apenas para a difusão “sem se encarregar do cuidado e da conservação dos filmes", pois guardava somente cópias para exibições. 
seio de nossos arquivos fílmicos, mas também e talvez principalmente como uma transformação nas discussões no cinema latino-americano em geral. Nos anos 1980, os ventos da Revolução se arrefecem, abrindo espaço para os debates sobre indústria e público - inclusive, em Cuba. Seria deveras ingênuo afirmar que testemunhamos nesse período, década de 1980, o surgimento de uma consciência de patrimônio audiovisual em nossos governantes e na nossa própria classe cinematográfica. Mas os debates em torno de temas industriais abrem, mesmo que displicentemente, a porta para a memória audiovisual, ainda que seja pelo viés mercadológico. É no meio de tais discussões, que realizadores, produtores, distribuidores e exibidores se indagam o que fazer e onde encontrar aquele "filme velho". Passam então a perguntar: existe uma cinemateca? Para que serve uma cinemateca?

\section{Referências Bibliográficas}

AMIEVA, M. "Cine Arte del SODRE en la conformación de un campo audiovisual en Uruguay: políticas públicas y acciones individuales”. Cine Documental, Buenos Aires, n. 6, 2012. Disponível em: <http://revista.cinedocumental.com.ar/6/ articulos_01.html>. Acesso em: 11 nov. 2015.

AVELLAR, J. C. A ponte clandestina. Rio de Janeiro/São Paulo: Ed. 34/Edusp, 1995.

BAECQUE, A. Cinefilia: invenção de um olhar, história de uma cultura 1944-1968. Trad. André Telles. São Paulo: Cosacnaify, 2011.

BEZERRA, L. [M. L. S. A. B. Lindner]. Políticas para a preservação audiovisual no Brasil (1995-2010) ou: "para que eles continuem vivos através de novos modos de vêlos". Tese (Doutorado) - Universidade Federal da Bahia, Salvador, 2014.

BORDE, R. Les cinémathèques. Laussane: L'Âge d'homme, 1983.

BORDE, R.; BUACHE, F. La crise des cinémathèques... et du monde. Lausanne: L'Âge d'homme, 1997.

COELHO, M. F. C. A experiência brasileira na conservação de acervos audiovisuais: um estudo de caso. Dissertação (Mestrado) - Universidade de São Paulo, São Paulo, 2009.

CORREA JÚNIOR, F. D. O cinema como instituição: a Federação Internacional de Arquivos de Filmes (1948-1960). Tese (Doutorado) - Universidade Estadual Paulista Júlio de Mesquita Filho, Assis, 2012.

Sex, money, social climbing, fantastic!: a lógica cultural dos anos de chumbo do cone sul e a história das cinematecas (arquivos/museus de cinema). Cadernos CEDEM, Assis. v. 2, nº 1, 2011, p. 27 - 47. 
UNESP, 2010.

A Cinemateca Brasileira: das luzes aos anos de chumbo. São Paulo: Ed.

CARRIL, M. M. "Cinemateca Uruguaya - entrevista con C. Dimitriu". Journal of film preservation. Bruxelas, $\mathrm{n}^{\circ}$. 79-80. abr., 2009. pp. 37-58. Disponível em: <http:// www.fiafnet.org/content/finFIAF_79\%201\%201.pdf>. Acesso em: 29 ago. 2015.

CHASKEL, P. Entrevista concedida a Fabián Núñez. 2015.

DEL VALLE DÁVILA, I. Cámaras en trance: el Nuevo Cine Latinoamericano, un proyecto cinematográfico subcontinental. Santiago: Cuarto Propio, 2014.

DOMÍNGUEZ, C. M. 24 ilusiones por segundo: la historia de Cinemateca Uruguaya. Montevidéu: Cinemateca Uruguaya, 2013.

FILMOTECA DE LA UNAM. Boletín CIDUCAL. México, n. 5, 2 época, out. 1984.

FLORES, S. El Nuevo Cine Latinoamericano y su dimensión continental: regionalismo e integración cinematográfica. Buenos Aires: Imago Mundi, 2013.

GALVÃO, M. R. E. Projeto Centro(s) Regional(is) de Preservação do Acervo Cinematográfico Latino-Americano. Tese (Livre-docência) - Universidade de São Paulo, São Paulo, 1991.

GETINO, O.; VELLEGGIA, S. El cine de las historias de la revolución: aproximación a las teorías y prácticas del cine político en América Latina (1967-1977). Buenos Aires: Altamira, 2002.

LEÓN FRÍAS, I. El nuevo cine latinoamericano de los años sesenta: entre el mito político y la modernidad fílmica. Lima: Universidad de Lima, 2013.

NÚÑEZ, F. "A preservação audiovisual segundo o Nuevo Cine Latinoamericano." In. III CONGRESO INTERNACIONAL DE LA ASAECA, 2012, Córdoba. Actas del III Congreso Internacional. Córdoba: AsAECA, 2012. Disponível em: <http:// www.asaeca.org/aactas/nu_ez_fabi_n_-_ponencia.pdf>. Acesso em: 29 ago. 2015.

QUENTAL, J. L. A. A preservação cinematográfica no Brasil e a construção de uma cinemateca na Belacap: a Cinemateca do Museu de Arte Moderna do Rio de Janeiro. Dissertação (Mestrado) - Universidade Federal Fluminense, Niterói, 2010.

RIVERA, N. "Um olhar a CLAIM: coordenadora latino-americana de arquivos de imagens em movimento". Catálogo CineOP - $9^{a}$ Mostra de Cinema de Ouro Preto. jun. 2014, p. 92 - 95.

SALINAS MUÑOZ, C.; STANGE MARCUS, H. Historia del Cine Experimental en la Universidad de Chile: 1957-1973. Santiago: Uqbar, 2008.

SOUZA, C. R. A Cinemateca Brasileira e a preservação de filmes no Brasil. Tese (Doutorado) - Universidade de São Paulo, São Paulo, 2009. 
UNIVERSIDAD NACIONAL AUTÓNOMA DE MÉXICO. Filmoteca de la UNAM 1960/1975. México: s.d.

VINCENOT, E. Historie du cinéma à Cuba, des origines à l'avènement de la révolution. Tese (Doutorado) - Universidade de Borgonha, Dijon, 2005, p. 496 - 525.

VV.AA. Por un cine latinoamericano: Encuentro de cineastas latinoamericanos en solidariedad con el pueblo y los cineastas de Chile (Caracas, Septiembre de 1974). Caracas: Rocinante, 1974.

VV.AA. Por un cine latinoamericano - Volumen II: V Encuentro de cineastas latinoamericanos (Mérida, 1977). Caracas: Rocinante, 1978.

submetido em: 07092015 | aprovado em: 22112015. 